\title{
The Paradigm of G Protein Receptor Transactivation: A Mechanistic Definition and Novel Example
}

\author{
Peter J. Little ${ }^{1,2,3,4, *}$, Micah L. Burch ${ }^{3,4}$, Sefaa Al-aryahi', \\ and Wenhua Zheng ${ }^{5}$ \\ ${ }^{1}$ Discipline of Pharmacy, School of Medical Sciences and ${ }^{2}$ Diabetes Complications \\ Group, Health Innovations Research Institute, RMIT University, Melbourne, Victoria, \\ Australia; ${ }^{3}$ Diabetes and Cell Biology Laboratory, BakerIDI Heart and Diabetes \\ Institute, Melbourne, Victoria, Australia; ${ }^{4}$ Monash University, Departments of \\ Medicine and Immunology, Central and Eastern Clinical School, Alfred Health, \\ Melbourne, Victoria, Australia; ${ }^{5}$ Neuropharmacology, School of Pharmaceutical \\ Sciences, Sun Yat-Sen University, Guangzhou, Guangdong, China \\ E-mail: peter.little@rmit.edu.au; micah.burch@bakeridi.edu.au; sefaa.al-aryahi@rmit.edu.au; \\ whzheng123@gmail.com
}

Received October 29, 2010; Revised February 28, 2011; Accepted March 1, 2011; Published March 22, 2011

Seven transmembrane G protein-coupled receptors are among the most common in biology and they transduce cellular signals from a plethora of hormones. As well as their own well-characterized signaling pathways, they can also transactivate tyrosine kinase growth factor receptors to greatly expand their own cellular repertoire of responses. Recent data in vascular smooth muscle cells have expanded the breadth of transactivation to include serine/threonine kinase receptors, specifically the receptor for transforming growth factor beta (TGF- $\beta$ ). Stimulation with endothelin and thrombin leads to the rapid formation of C-terminal phosphorylated Smad2, which is the immediate product of activation of the TGF- $\beta$ receptor. Additionally, it appears that no definition of transactivation based on mechanism is available, so we have provided a definition involving temporal aspects and the absence of de novo protein synthesis. The phenomenon of transactivation is an important biochemical mechanism and potential drug target in multiple diseases.

KEYWORDS: G protein-coupled receptors, protein kinase receptors, transactivation, and definition

G protein-coupled receptors (GPCRs) are one of the largest families of receptors in biology and are a major category of targets for therapeutic agents[1,2]. GPCR signaling, both at the receptor level and downstream pathways of GPCRs, has been the subject of intense research over several decades and multiple pathways have been described[3,4,5,6]. One of the most interesting pathways involves the transactivation of growth factor receptors, specifically protein tyrosine kinase (PTK) receptors, the activation of which immensely expands the range of cellular functions attributable to GPCRs $[6,7,8]$. 
Downstream pathways include GPCR activation of phospholipase $\mathrm{C}$, and the generation of inositol 1,4,5-trisphosphate $\left(\mathrm{IP}_{3}\right)$ and diacylglycerol[9] and transactivation of receptor tyrosine kinases[10]. Using angiotensin II (AII) receptor activation in vascular smooth muscle cells and responses in blood vessels as an example, the functional consequences of the multiple downstream signal pathway are the production of $\mathrm{IP}_{3}$ leading to the immediate release of calcium from the sarcoplasmic reticulum and acute regulation of vascular tone, a response occurring in seconds[11]. The generation of diacylglycerol leads to the activation of protein kinase $\mathrm{C}$ and a cascade leading to the phosphorylation of proteins associated with vascular contraction and the maintenance of a medium-term contraction in a process extending over hours[12,13]. In 1996, Ulrich and colleagues discovered that a GPCR agonist such as AII could lead to the "transactivation" of a protein tyrosine-coupled receptor, specifically the epidermal growth factor (EGF) receptor, leading to phosphorylation of EGFR and the generation of products such as phospho ERK, which are downstream of the EGFR[7,8]. This is very important because GPCR agonists are not generally capable of generating a cell growth signal, but the ability to transactivate a fully competent growth factor receptor, such as the EGFR, gives the GPCR the ability to generate a full-blown cell growth response. Since this original demonstration, there have been many examples in which GPCR agonists, including AII, thrombin, and endothelin, can transactivate multiple PTK receptors, including PDGF, FGF, and IGF-1[14,15,16,17,18,19]. The transactivation of tyrosine kinase receptors such as PDGF and EGF leads to the long-term regulation of vascular tone through effects on vascular smooth muscle cell proliferation and the production of extracellular matrix, with these effects occurring over days or longer, representing remodeling that alters the structure of a blood vessel in response to a pathological stimuli $[6,7,20,21,22]$. Thus, transactivation leading to vascular remodeling is a very important biological process.

Thus far, the paradigm of GPCR signaling involving receptor transactivation has been limited to PTK receptors. There have been many studies since the original observation and multiple distinct mechanisms have been discovered for the transition of the signal from the GPCR to the PTK receptor[10,23]. These processes have involved intracellular signaling pathways such as calcium ions and reactive oxygen species, and an intriguing extracellular pathway in which GPCR occupation leads to the generation and autocrine/paracrine action of heparin-binding EGF (HB-EGF), which activates EGFRs[24,25]. All of these distinct processes have been included under the term receptor "transactivation".

We have recently discovered that two GPCR agonists can independently activate their respective GPCRs, leading to the generation of C-terminal phosphorylated Smad transcription factor (phosphoSmad2C or pSmad2)[26,27], which is the immediate downstream product of activation of the serine/threonine kinase activity of the transforming growth factor beta (TGF- $\beta$ ) receptor (T $\beta R I)$, also known as activin-like kinase V (ALK V)[28,29]. The generation of phosphoSmad2C is blocked by both inhibitors of the primary GPCR: bosentan for endothelin receptors, and JNJ5177094 or SCH 79797 for protease activated receptors (PAR)-1 for thrombin[28,29]. Critically, both responses are also blocked by the widely used and selective ALK V inhibitor SB431542[28,29,30]. This pathway fits the use of the term "transactivation" as used in the literature relating the GPCR activation of receptors. There have been several examples of this GPCR to S/TK receptor transactivation where the authors have not used the term transactivation in their descriptions of the interaction[31,32,33,34].

There have been several explanations or definitions of the term transactivation in the context of receptor to receptor transactivation, but none that extended to an inclusion of the mechanism of the interaction. Berry and colleagues provided the first definition as simply "the process whereby ligand stimulation of one receptor leads to activation of another, distinct receptor"[35]. Wetzker and Bohmer[36] offered an explanation of transactivation as being when one receptor transactivates a heterologous receptor. It should be noted that receptor transactivation as considered here is distinct from the transactivation of genes by transcription factors[36]. We thus propose the mechanistic definition that receptor transactivation is "the agonist occupancy of its cognate GPCR complex which leads in a relatively short time and in the absence of 'de novo' protein synthesis to the activation of and cytosolic generation of the immediate downstream product(s) of a second cell surface protein kinase receptor" (Fig. 1). Obviously, it is necessary to add a conceptual component that takes into account the temporal characteristics 


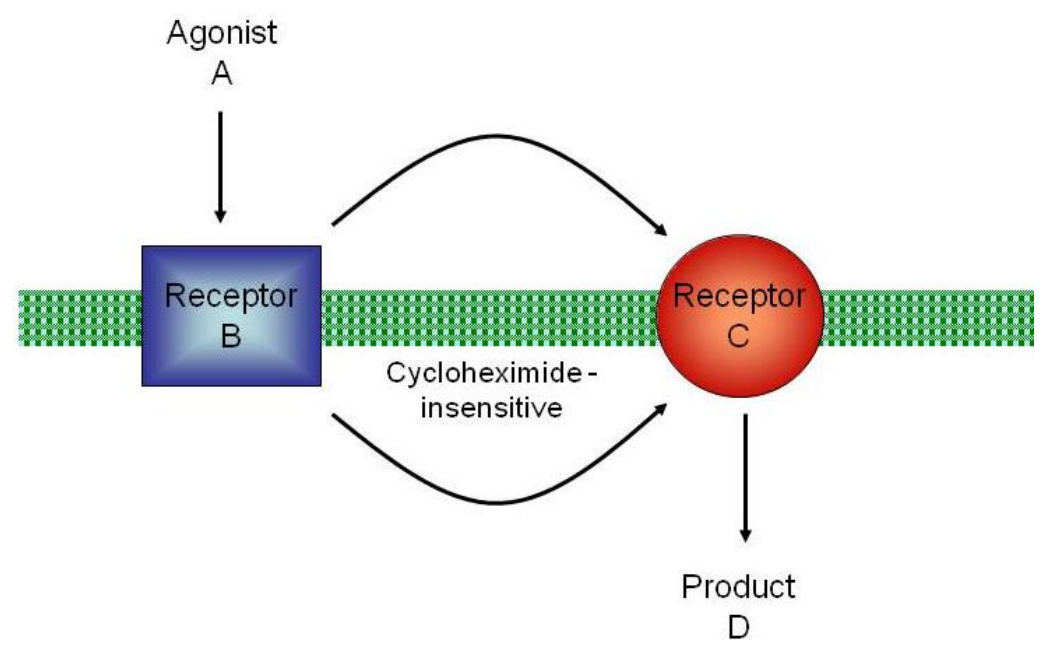

FIGURE 1. Model of GPCR receptor to protein kinase receptor transactivation. An agonist A of a receptor B, in this case a GPCR, leads via a mechanism, which is insensitive to the protein synthesis inhibitor cycloheximide, to the activation of a second receptor $\mathrm{C}$, in this case a protein kinase receptor, and the formation of the product $\mathrm{D}$, a phosphorylated signaling intermediate often being a transcription factor. The process is required to occur in a relatively short time frame to constitute "transactivation". A specific new example is given in Fig. 2.

of the response because long-term receptor occupancy can lead to a multitude of secondary and tertiary interactions, and certainly the gene to mRNA to protein sequence should be excluded from the definition of transactivation.

In view of the literature on GPCR transactivation of PTK receptors, the definition should be taken to include all mechanisms that lead to the generation of the index product, and it should include mechanisms that are intra/extracellular and mechanisms that may involve, but also may not involve, a direct interaction between the two receptors of interest. The proposed definition includes the concept of the pathway being not dependent on de novo protein synthesis. This arises from consideration of the involvement of transcription and translation in the definition of receptor "transactivation". Should the occurrence of transcription or translation, meaning in practical terms that the response is sensitive to actinomycin D or cycloheximide, respectively, be interpreted as meeting or not meeting the definition of transactivation? We would suggest that sensitivity to cycloheximide should exclude the pathway from the definition of receptor to receptor "transactivation". In most cases, it is to be expected that this will also be picked up by the temporal caveat in that a process requiring transcription and translation of a new protein is likely to take many hours and therefore extend beyond the time indicated above to which the use of the term "transactivation" should be applied.

Receptor to heterologous receptor transactivation has implications in the identification of drug targets for various diseases. T $\beta R I$ stimulates the synthesis of collagen by vascular smooth muscle and other cells (fibroblasts), leading to excess collagen deposition and ultimately organ fibrosis as the eventual pathology[32,37,38]. Accordingly, T $\beta R I$ appears to be a valid target to prevent the fibrotic actions of TGF- $\beta$. However, receptor transactivation raises the possibility that the apparent primary response is hiding or masking a response that is due to receptor transactivation. In our own studies, we have used proteoglycan and glycosaminoglycan synthesis as a functional readout because of its association with increased lipid binding in the context of the initiation of atherosclerosis[39,40,41,42]. The actions of thrombin and endothelin to generate phosphoSmad2C through transactivation of T $\beta R I$ are fully functional when assessed as the ability to stimulate the synthesis of the proteoglycan biglycan and cause 
glycosaminoglycan elongation in human vascular smooth muscle cells[28,29]. Hence, it is possible that a GPCR stands behind a growth factor receptor and in the current case, a GPCR agonist such as thrombin or endothelin may be playing a previously unrecognized role in the stimulation of proteoglycan synthesis via the transactivation of T $\beta$ RI. These pathways warrant full investigation for their occurrence in vivo and their potential role in multiple pathologies.

In conclusion, we have recently found that the paradigm of GPCR transactivation can be extended to include the transactivation of the serine/threonine kinase receptors, specifically T $\beta$ RI (Fig. 2). In the apparent absence of a definition of receptor transactivation involving mechanism, we have provided a definition that includes the response being relatively rapid, and not involving de novo protein synthesis as an indication that the response is direct and does not involve the secondary or tertiary generation of new proteins to affect the transactivation. The implications of receptor transactivation are as previously recognized by others[43], that the apparent primary response such as the generation of a phosphorylated transcription factor may not arise solely from the actions of the protein kinase receptor by its cognate ligand, but may involve the earlier activation of a GPCR and transactivation. A further implication is that the therapeutic target may be the GPCR.
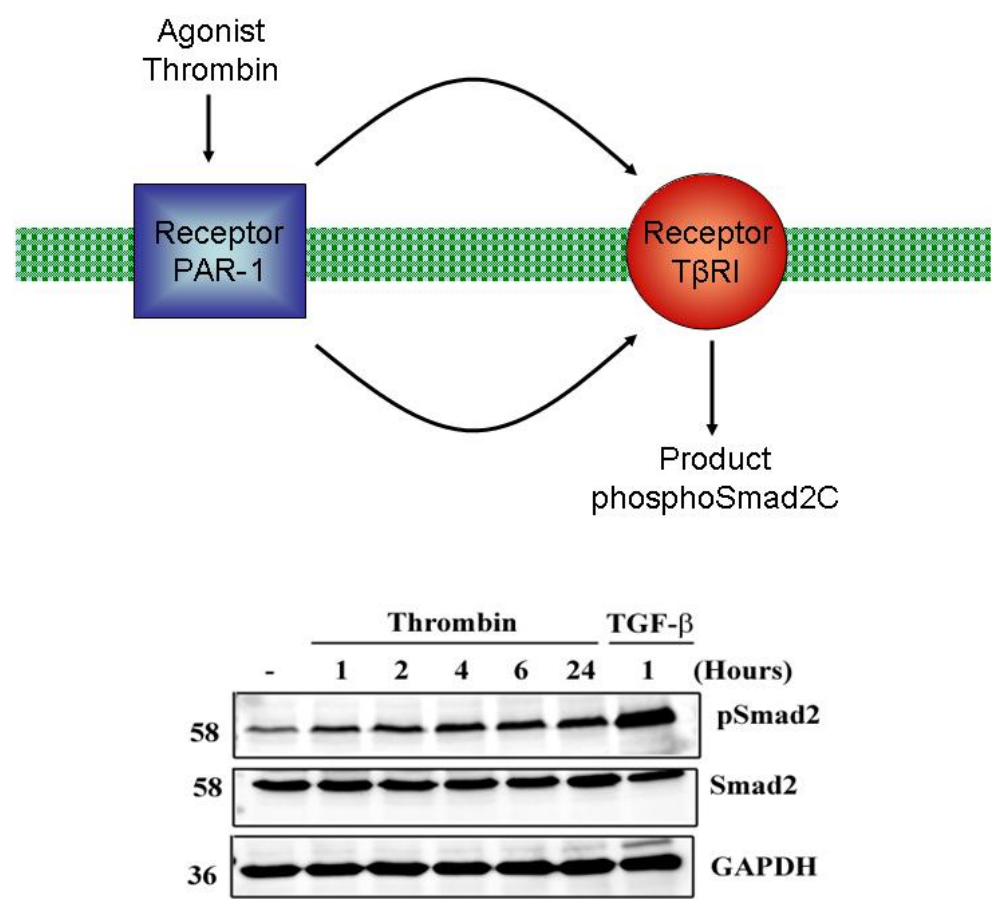

FIGURE 2. A novel example of G protein to protein Ser/Thr kinase receptor "transactivation". Although the paradigm has been previously restricted to the GPCR transactivation of PTK receptors, it has recently been reported that GPCRs can transactivate the serine/threonine kinase activity of the T $\beta R I$ receptor, leading to the rapid formation of phosphoSmad2. The data show that the level of pSmad2C is clearly increased by $1 \mathrm{~h}$, and it is explained in the text that this response is blocked by both inhibitors of the thrombin receptor (PAR-1) and TRRI. (The research shown was originally published in Burch et al.[28]. (C) The American Society for Biochemistry and Molecular Biology.) 


\section{REFERENCES}

1. Dupree, C.S. (2010) Primary prevention of heart failure: an update. Curr. Opin. Cardiol. 22, 478-483.

2. Schieppati, A. and Remuzzi, G. (2004) Fighting renal diseases in poor countries: building a global fund with the help of the pharmaceutical industry. J. Am. Soc. Nephrol. 15, 704-707.

3. Smith, N.J. and Luttrell, L.M. (2006) Signal switching, crosstalk, and arrestin scaffolds: novel G protein-coupled receptor signaling in cardiovascular disease. Hypertension 48, 173-179.

4. Lefkowitz, R.J. (2007) Seven transmembrane receptors: a brief personal retrospective. Biochim. Biophys. Acta 1768, 748-755.

5. Lefkowitz, R.J. (2007) Seven transmembrane receptors: something old, something new. Acta Physiol. (Oxf.) 190, 919.

6. Ferguson, S.S., Barak, L.S., Zhang, J., and Caron, M.G. (1996) G-protein-coupled receptor regulation: role of Gprotein-coupled receptor kinases and arrestins. Can. J. Physiol. Pharmacol. 74, 1095-1110.

7. Daub, H., Weiss, F.U., Wallasch, C., and Ullrich, A. (1996) Role of transactivation of the EGF receptor in signalling by G-protein-coupled receptors. Nature 379, 557-560.

8. Daub, H., Wallasch, C., Lankenau, A., Herrlich, A., and Ullrich, A. (1997) Signal characteristics of G proteintransactivated EGF receptor. EMBO J. 16, 7032-7044.

9. Gerthoffer, W.T. (2005) Signal-transduction pathways that regulate visceral smooth muscle function. III. Coupling of muscarinic receptors to signaling kinases and effector proteins in gastrointestinal smooth muscles. Am. J. Physiol. Gastrointest. Liver Physiol. 288, G849-853.

10. Almendro, V., Garcia-Recio, S., and Gascon, P. (2010) Tyrosine kinase receptor transactivation associated to G protein-coupled receptors. Curr. Drug Targets 11, 1169-1180.

11. Lee, C.H., Poburko, D., Sahota, P., Sandhu, J., Ruehlmann, D.O., and van Breemen, C. (2001) The mechanism of phenylephrine-mediated $[\mathrm{Ca}(2+)](\mathrm{i})$ oscillations underlying tonic contraction in the rabbit inferior vena cava. $J$. Physiol. 534, 641-650.

12. Gorlach, C., Benyo, Z., and Wahl, M. (1998) Endothelin-1-induced contraction in cerebral vessels mediated by phospholipase C/protein kinase C cascade. Kidney Int. Suppl. 67, S224-225.

13. Griendling, K.K., Tsuda, T., Berk, B.C., and Alexander, R.W. (1989) Angiotensin II stimulation of vascular smooth muscle cells. Secondary signalling mechanisms. Am. J. Hypertens. 2, 659-665.

14. Andresen, B.T., Linnoila, J.J., Jackson, E.K., and Romero, G.G. (2003) Role of EGFR transactivation in angiotensin II signaling to extracellular regulated kinase in preglomerular smooth muscle cells. Hypertension 41, 781-786.

15. Saito, Y. and Berk, B.C. (2001) Transactivation: a novel signaling pathway from angiotensin II to tyrosine kinase receptors. J. Mol. Cell. Cardiol. 33, 3-7.

16. Zahradka, P., Storie, B., and Wright, B. (2009) IGF-1 receptor transactivation mediates Src-dependent cortactin phosphorylation in response to angiotensin II. Can. J. Physiol. Pharmacol. 87, 805-812.

17. Hua, H., Munk, S., and Whiteside, C.I. (2003) Endothelin-1 activates mesangial cell ERK1/2 via EGF-receptor transactivation and caveolin-1 interaction. Am. J. Physiol. Renal Physiol. 284, F303-312.

18. Kanda, Y., Mizuno, K., Kuroki, Y., and Watanabe, Y. (2001) Thrombin-induced p38 mitogen-activated protein kinase activation is mediated by epidermal growth factor receptor transactivation pathway. Br. J. Pharmacol. 132, $1657-1664$.

19. Vacca, F., Bagnato, A., Catt, K.J., and Tecce, R. (2000) Transactivation of the epidermal growth factor receptor in endothelin-1-induced mitogenic signaling in human ovarian carcinoma cells. Cancer Res. 60, 5310-5317.

20. Takahashi, M. (2006) The role of endothelin-1 in vascular remodeling in vivo. Cardiovasc. Res. 71, 4-5.

21. Heagerty, A., Aalkjaer, C., Bund, S., Korsgard, N., and Mulvany, M. (1993) Small artery structure in hypertension. Hypertension 21, 391-397.

Viero, C., Shibuya, I., Kitamura, N., Verkhratsky, A., Fujihara, H., Katoh, A., Ueta, Y., Zingg, H.H., Chvatal, A., Sykova, E., and Dayanithi, G. (2010) REVIEW: Oxytocin: crossing the bridge between basic science and pharmacotherapy. CNS Neurosci. Ther. 16, e138-156.

23. Feng, P.H., Hsiung, T.C., Kuo, H.P., and Huang, C.D. (2010) Cross-talk between bradykinin and epidermal growth factor in regulating IL-6 production in human airway smooth muscle cells. Chang Gung Med. J. 33, 92-99.

24. Yan, Y., Shirakabe, K., and Werb, Z. (2002) The metalloprotease Kuzbanian (ADAM10) mediates the transactivation of EGF receptor by G protein-coupled receptors. J. Cell Biol. 158, 221-226.

25. Frank, G.D. and Eguchi, S. (2003) Activation of tyrosine kinases by reactive oxygen species in vascular smooth muscle cells: significance and involvement of EGF receptor transactivation by angiotensin II. Antioxid. Redox Signal. 5, 771-780.

26. Derynck, R. and Zhang, Y.E. (2003) Smad-dependent and Smad-independent pathways in TGF-beta family signalling. Nature 425, 577-584.

27. Massague, J. (2003) Integration of Smad and MAPK pathways: a link and a linker revisited. Genes Dev. 17, 29932997.

28. Burch, M.L., Ballinger, M.L., Yang, S.N., Getachew, R., Itman, C., Loveland, K., Osman, N., and Little, P.J. (2010) Thrombin stimulation of proteoglycan synthesis in vascular smooth muscle is mediated by protease-activated receptor-1 transactivation of the transforming growth factor beta type I receptor. J. Biol. Chem. 285, 26798-26805. 
29. Little, P.J., Burch, M.L., Getachew, R., Al-aryahi, S., and Osman, N. (2010) Endothelin-1 stimulation of proteoglycan synthesis in vascular smooth muscle is mediated by endothelin receptor transactivation of the transforming growth factor-[beta] type I receptor. J. Cardiovasc. Pharmacol. 56, 360-368.

30. Inman, G.J., Nicolas, F.J., Callahan, J.F., Harling, J.D., Gaster, L.M., Reith, A.D., Laping, N.J., and Hill, C.S. (2002) SB-431542 is a potent and specific inhibitor of transforming growth factor-beta superfamily type I activin receptorlike kinase (ALK) receptors ALK4, ALK5, and ALK7. Mol. Pharmacol. 62, 65-74.

31. Sorescu, D. (2006) Smad3 mediates angiotensin II- and TGF-beta1-induced vascular fibrosis: Smad3 thickens the plot. Circ. Res. 98, 988-989.

32. Leask, A. (2010) Potential therapeutic targets for cardiac fibrosis: TGFbeta, angiotensin, endothelin, CCN2, and PDGF, partners in fibroblast activation. Circ. Res. 106, 1675-1680.

33. Xu, M.Y., Porte, J., Knox, A.J., Weinreb, P.H., Maher, T.M., Violette, S.M., McAnulty, R.J., Sheppard, D., and Jenkins, G. (2009) Lysophosphatidic acid induces alphavbeta6 integrin-mediated TGF-beta activation via the LPA2 receptor and the small $G$ protein $G$ alpha(q). Am. J. Pathol. 174, 1264-1279.

34. Jenkins, R.G., Su, X., Su, G., Scotton, C.J., Camerer, E., Laurent, G.J., Davis, G.E., Chambers, R.C., Matthay, M.A., and Sheppard, D. (2006) Ligation of protease-activated receptor 1 enhances alpha(v)beta6 integrin-dependent TGFbeta activation and promotes acute lung injury. J. Clin. Invest. 116, 1606-1614.

35. Berry, C., Touyz, R., Dominiczak, A.F., Webb, R.C., and Johns, D.G. (2001) Angiotensin receptors: signaling, vascular pathophysiology, and interactions with ceramide. Am. J. Physiol. Heart Circ. Physiol. 281, H2337-2365.

36. Wetzker, R. and Bohmer, F.D. (2003) Transactivation joins multiple tracks to the ERK/MAPK cascade. Nat. Rev. Mol. Cell Biol. 4, 651-657.

37. Cutroneo, K.R. (2007) TGF-beta-induced fibrosis and SMAD signaling: oligo decoys as natural therapeutics for inhibition of tissue fibrosis and scarring. Wound Repair Regen. 15(Suppl 1), S54-60.

38. Ruiz-Ortega, M., Rodriguez-Vita, J., Sanchez-Lopez, E., Carvajal, G., and Egido, J. (2007) TGF-beta signaling in vascular fibrosis. Cardiovasc. Res. 74, 196-206.

39. Nigro, J., Dilley, R.J., and Little, P.J. (2002) Differential effects of gemfibrozil on migration, proliferation and proteoglycan production in human vascular smooth muscle cells. Atherosclerosis 162, 119-129.

40. Tannock, L., Little, P.J., Wight, T.N., and Chait, A. (2002) Arterial smooth muscle cell proteoglycans synthesized in the presence of glucosamine demonstrate reduced binding to LDL. J. Lipid Res. 43, 149-157.

41. Little, P.J., Osman, N., and O'Brien, K.D. (2008) Hyperelongated biglycan: the surreptitious initiator of atherosclerosis. Curr. Opin. Lipidol. 19, 448-454.

42. Gustafsson, M., Levin, M., Skalen, K., Perman, J., Friden, V., Jirholt, P., Olofsson, S.O., Fazio, S., Linton, M.F., Semenkovich, C.F., Olivecrona, G., and Boren, J. (2007) Retention of low-density lipoprotein in atherosclerotic lesions of the mouse: evidence for a role of lipoprotein lipase. Circ. Res. 101, 777-783.

43. Shah, B.H. and Catt, K.J. (2004) GPCR-mediated transactivation of RTKs in the CNS: mechanisms and consequences. Trends Neurosci. 27, 48-53.

\section{This article should be cited as follows:}

Little, P.J., Burch, M.L., Al-aryahi, S., and Zheng, W. (2011) The paradigm of G protein receptor transactivation: a mechanistic definition and novel example. TheScientificWorldJOURNAL 11, 709-714. DOI 10.1100/tsw.2011.75. 

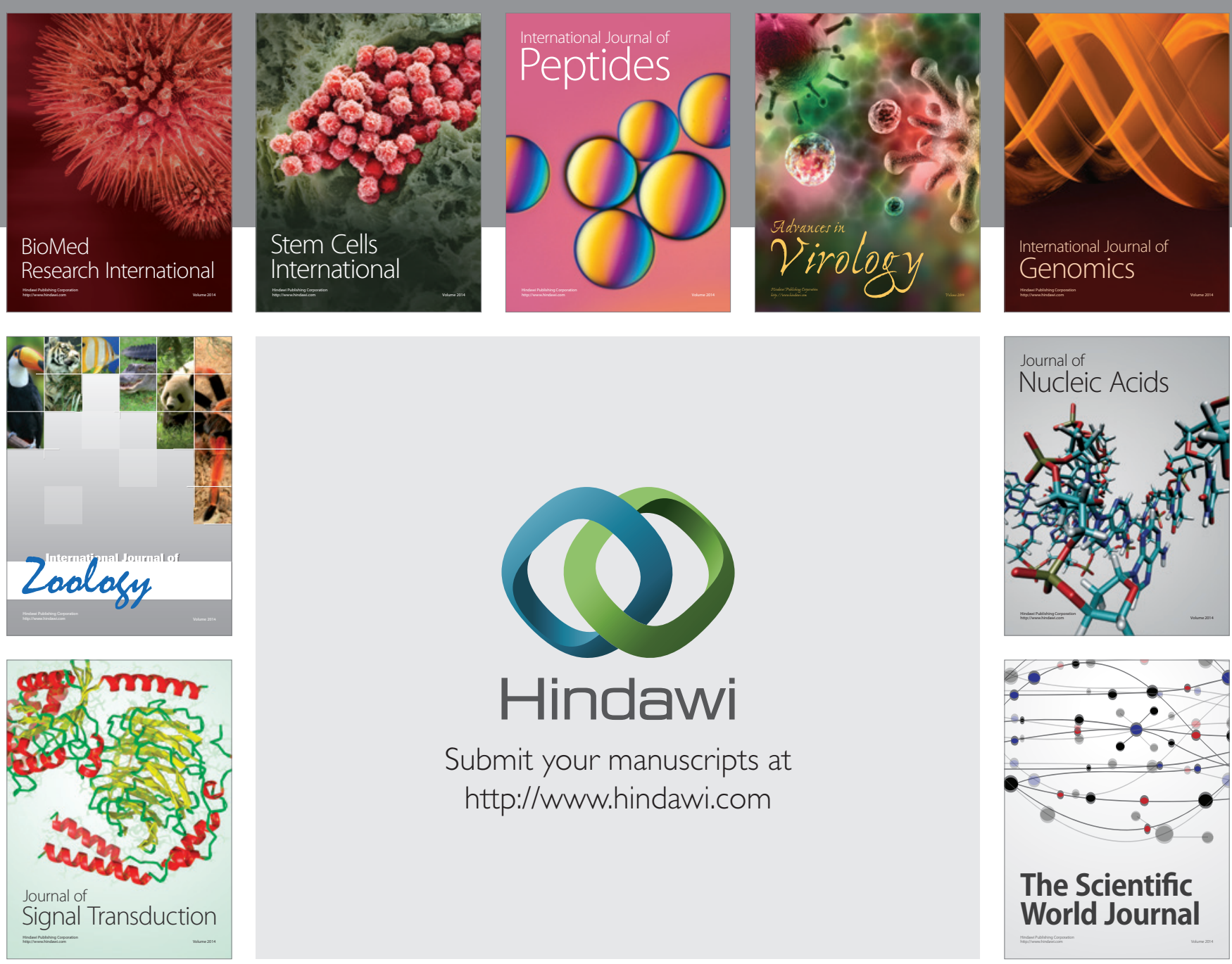

Submit your manuscripts at

http://www.hindawi.com
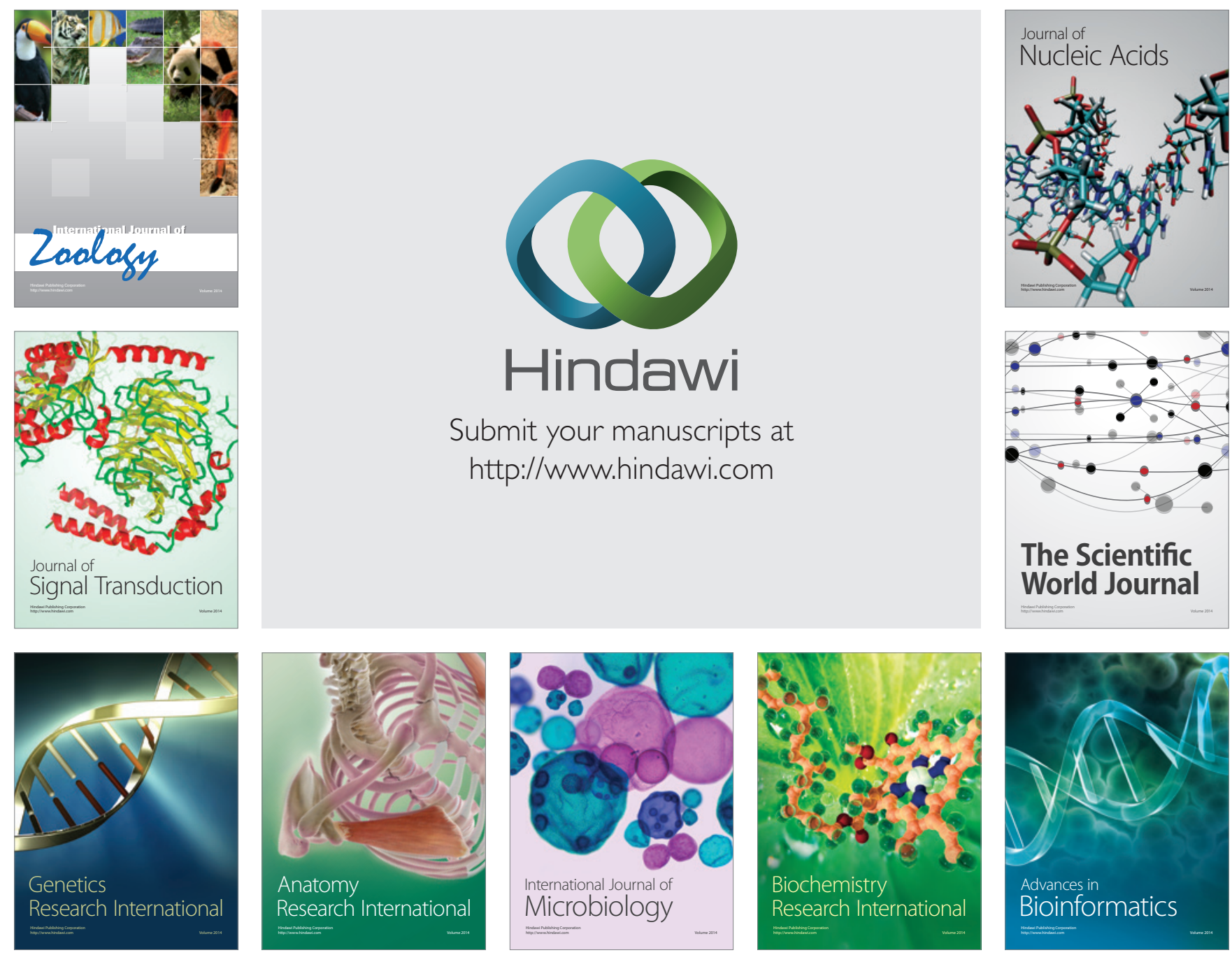

The Scientific World Journal
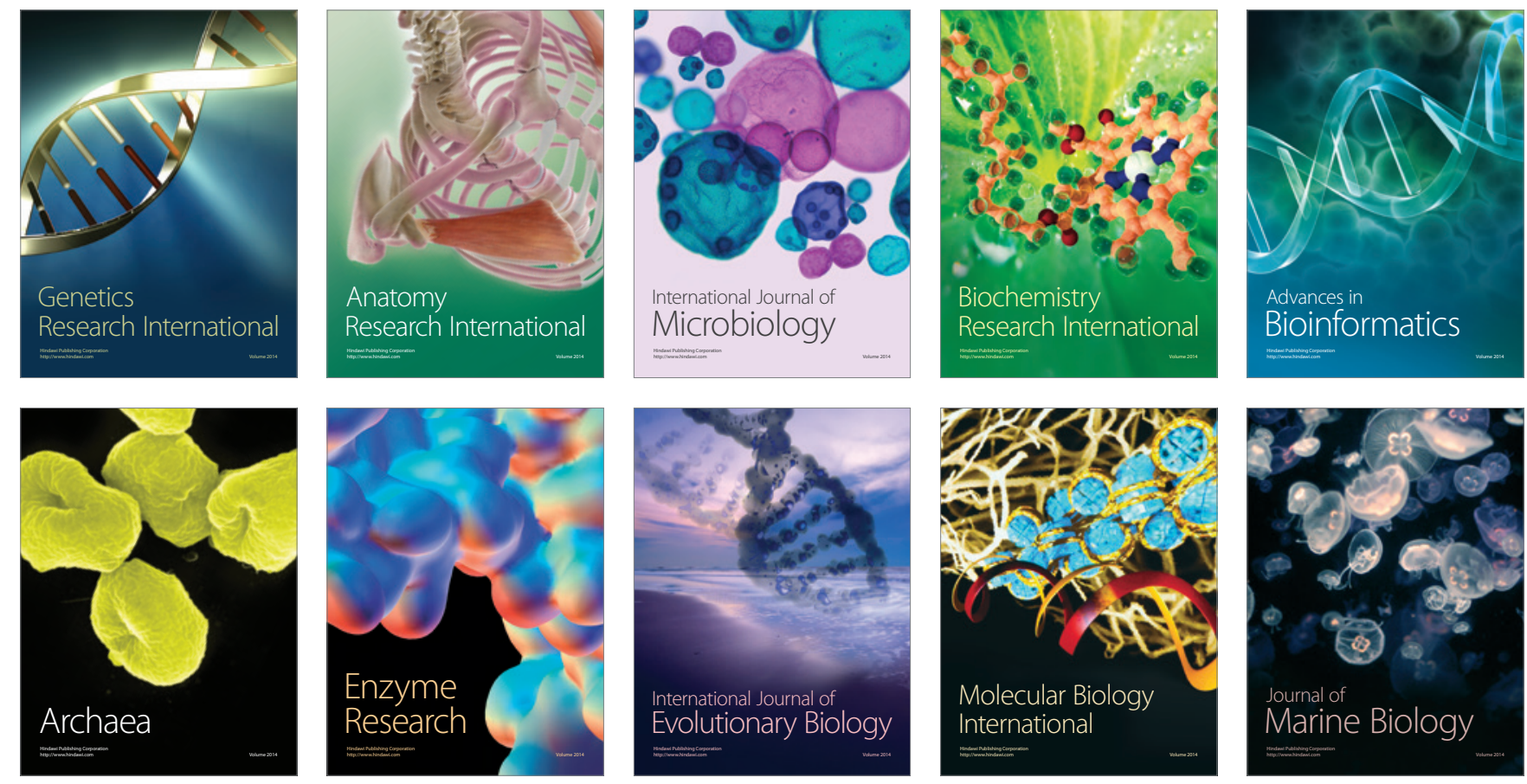